\title{
Isolation of $\beta$-Amyrin from the Fungus Aspergillus nidulans
}

\author{
By MICHAEL A. GEALT \\ Department of Biological Sciences, Drexel University, 32nd and Chestnut Streets, Philadelphia, \\ Pennsylvania 19104, U.S.A.
}

(Received 30 June 1982; revised 20 September 1982)

The pentacyclic triterpene alcohol $\beta$-amyrin, which is commonly found in plants, was isolated
from wild-type cultures of the ascomycete fungus $A$ spergillus nidulans. The isolated $\beta$-amyrin was
characterized by TLC, GLC, and HPLC and produced identical mass and ${ }^{1} \mathrm{H}$ NMR spectra to
those of authentic $\beta$-amyrin. This material was isolated from static (non-shaking) cultures.

\section{INTRODUCTION}

While the sterols are the most common eukaryotic biochemical consequence of squalene cyclization, other end-products have been observed. These include tetracyclic compounds such as euphol and euphol-like materials in plants and pentacyclic compounds such as tetrahymanol in Tetrahymena pyriformis, hopene-I in ferns and lichens, and the amyrins ( $\alpha$ - and $\beta$-) in several plant species (Boar \& Allen, 1973; Nes \& McKean, 1977). The presence (or absence) of these synthetic products in an organism has been used as an aid in taxonomic catagorization; this characterization presumes that the spectrum of genetic capabilities is being expressed at the time of examination. The finding of specific compounds in uncharacteristic species may indicate either convergent evolutionary processes or the maintenance of unexpressed genetic potential across vast phylogenetic distances.

In a previous report (Shapiro \& Gealt, 1982), we identified lanosterol as the first cyclization product of squalene with ergosterol as the ultimate sterol in $A$. nidulans. We report here that this organism is capable of producing a second cyclization product, $\beta$-amyrin (Fig. 1), under stationary growth conditions in a defined medium. This is the first report of this compound in the aspergilli and one of the rare reports of it in fungi.

\section{METHODS}

Organism and growth conditions. Aspergillus nidulans FGSC-4 was grown in a defined glucose/salts medium described previously (Adler et al., 1981). Stationary (non-shaking) cultures were grown for $8 \mathrm{~d}$ at $30^{\circ} \mathrm{C}$ using an inoculum of $10^{6}$ conidia $\mathrm{ml}^{-1}$. Cells were collected by filtration through Miracloth (Chicopee Mills, Inc., N.Y.). as described previously (Gealt et al., 1976) and extracted immediately.

Lipid extraction. Cells were extracted with methanol/chloroform $(2: 1, v / v)$ as described by Kates (1975). During the extraction, cells were homogenized in a Sorvall Omni-Mixer for $1 \mathrm{~min}$ at maximum speed to ensure complete removal of lipid material. The extracts were fractionated by TLC on Silica Gel 60 using a mobile phase of benzene/ethyl acetate $(80: 20, \mathrm{v} / \mathrm{v})$. Materials co-migrating with authentic ergosterol (a 4-desmethyl sterol) and lanosterol (a 4,4-dimethyl sterol) were extracted twice from the silica with chloroform and once with anhydrous diethyl ether. The major component of the dimethyl sterol fraction was further purified by preparative HPLC on a C-18 reverse-phase column ( $\mu$-Bondapak, Waters, Inc.) using a mobile phase of acetonitrile/methanol $(90: 10, \mathrm{v} / \mathrm{v})$.

Analytical methods. GLC was performed on XE-60 (1\%) on Chromosorb Q, 100-200 mesh, at $240{ }^{\circ} \mathrm{C}$ using a Perkin Elmer gas chromatograph, model 3B, with a flame-ionization detector. All retention times are given relative to cholesterol [relative retention time $(R R T)=1 \cdot 00$ ]. Analytical HPLC was performed on a C-18 reversephase column (Zorbax ODS, Du Pont, Inc.) at $45^{\circ} \mathrm{C}$ using a UV detector (either an LDC Spectomonitor III, Laboratory Data Control, or an LC-75, Perkin Elmer Co., equipped for UV wavelength scanning). Retention values are reported as $\alpha_{c}\left[\alpha_{c}=\left(k_{\text {sample }}^{\prime}\right) /\left(k_{\text {cholesterol }}^{\prime}\right)\right]$. Direct-probe mass spectral (MS) analysis was performed on a Finnegan Series 4021 GLC-MS instrument with a Series 6000 data system. Proton nuclear magnetic resonance 
(a)<smiles>CCCCCCCC=C(C)CCCC(C)=CCCC=C(C)C</smiles>

(b)<smiles>CC1(C)CCC2(C)CCC3(C)C(=CCC4C5(C)CCCC(C)(C)C5CCC43C)C2C1</smiles><smiles>CCCCC(C)C1CCC2(C)C3=C(CCC12C)C1(C)CCC(O)C(C)(C)C1CC3</smiles>

(d)<smiles>CC(C)C(C)/C=C/C(C)C1CCC2C3=CC=C4CC(O)CCC4(C)C3CCC21C</smiles>

Fig. 1. The cyclization products of squalene in $A$. nidulans. Squalene (a) is converted to the pentacycle $\beta$ amyrin $(b)$ and to the tetracycle lanosterol $(c)$. The lanosterol is converted to ergosterol $(d)$, the predominant sterol of this organism.

$\left({ }^{1} \mathrm{H}\right.$ NMR) spectra were obtained at $360 \mathrm{MHz}$ at ambient temperature on a Bruker instrument, model WH-360, in $\mathrm{CDCl}_{3}$ with $\mathrm{Si}\left(\mathrm{CH}_{3}\right)_{4}$ as internal standard, at the National Institutes of Health sponsored NMR regional facility at the University of Pennsylvania, Philadelphia, PA, U.S.A. Authentic $\beta$-amyrin (Pierce Chemical Co.) was the gift of W. R. Nes (Drexel University).

\section{RESULTS}

Lipids from 8-day static cultures of $A$. nidulans were extracted and separated by TLC. In addition to a dense band of material co-migrating with authentic 4-desmethyl sterol (ergosterol), a second band was observed in the sterol region of the TLC co-migrating with authentic 4,4dimethyl sterol (lanosterol). Both regions were collected from the TLC and the lipids were extracted from the silica for further examination.

The 4-desmethyl material exhibited characteristics consistent with authentic ergosterol: a GLC RRT $=1.33$; an HPLC $\alpha_{\mathrm{c}}=0.72$; the MS fragmentations at $m / e 396\left(\mathbf{M}^{+}, 72 \%\right), 378$ $\left(\mathrm{M}^{+}-\mathrm{H}_{2} \mathrm{O}, 6 \%\right), 363\left(\mathrm{M}^{+}-\mathrm{H}_{2} \mathrm{O},-\mathrm{CH}_{3}, 94 \%\right), 337\left(\mathrm{M}^{+}-\mathrm{H}_{2} \mathrm{O},-\mathrm{C}_{3} \mathrm{H}_{5}, 57 \%\right), 253$ $\left(\mathrm{M}^{+}-\mathrm{H}_{2} \mathrm{O}\right.$, - side chain, $\left.100 \%\right)$, and $211\left(\mathrm{M}^{+}-\mathrm{H}_{2} \mathrm{O},-\right.$ side chain, $\left.-\mathrm{C}_{3} \mathrm{H}_{6}, 94 \%\right)$; and ${ }^{1} \mathrm{H}$ NMR absorptions, in p.p.m. shift $(\delta)$ from $\mathrm{Si}\left(\mathrm{CH}_{3}\right)_{4}$ at 0.63 [C-18(s)], 0.82 and 0.84 [C-26,27(d), $\mathrm{J}=7 \mathrm{~Hz}$ ], 0.91 [C-28(d), $\mathrm{J}=7 \mathrm{~Hz}$ ], 0.94 [C-19(s)] and 1.03 [C-21(d), $\mathrm{J}=6 \mathrm{~Hz}$ ].

The 4,4-dimethyl region contained a major peak with a GLC retention at RRT $=1.63(72 \%$ of the total material) and minor peaks at $1.25(1 \%), 1.39(1 \%)$ and $1.86(27 \%)$. The major band was further purified by preparative HPLC. This HPLC-purified material was characterized by GLC, which indicated that the component at RRT $=1.86$ was removed, resulting in a sample composition of components at RRT $=1.63(92 \%), 1.25(4 \%)$, and $1.39(4 \%)$. Authentic $\beta$-amyrin also had an RRT $=1.63$, while lanosterol, the dimethyl sterol precursor of ergosterol in nonphotosynthetic organisms, has an RRT $=1 \cdot 48$. Another triterpene pentacycle, $\alpha$-amyrin, has an $\mathrm{RRT}=1.82$.

When the purified $A$. nidulans material with RRT $=1.63$ was examined by analytical HPLC, it exhibited an $\alpha_{c}=0.91$. Authentic $\bar{\beta}$-amyrin also had an $\alpha_{c}=0.91\left(\alpha\right.$-amyrin had an $\left.\alpha_{c}=0.99\right)$. 
The MS of the amyrins is characterized by an $\mathrm{M}^{+}$of $m / e 426$ and a major fragmentation yielding a component of $m / e 218$ (Budzikiewicz et al., 1964). The fragmentation of the $A$. nidulans component was: $m / e 426\left(\mathrm{M}^{+}, 1 \%\right), 275(1 \%), 257(1 \%), 218(100 \%), 203(47 \%), 189(33 \%), 175$ $(20 \%)$ and $161(20 \%)$. Authentic $\beta$-amyrin yielded fragments of $m / e 426\left(\mathrm{M}^{+}, 2 \%\right), 411$ $\left(\mathrm{M}^{+}-\mathrm{CH}_{3}, 0.75 \%\right), 275(4 \cdot 5 \%), 257(2 \%), 218(100 \%), 203(21 \%), 189(20 \%), 175(12 \%)$ and 161 $(20 \%)$. The ${ }^{1} \mathrm{H}$ NMR at $360 \mathrm{MHz}$ of both the $A$. nidulans component and the authentic $\beta$-amyrin produced singlet peaks at $\delta: 0.79,0.83,0.87,0.93,0.96,0.99$ and 1.13 p.p.m. The peak at 0.87 was the strongest, probably representing two singlets from the compound.

Quantitative GLC analysis of lipid extracted from statically grown $A$. nidulans indicated that the material at RRT $=1.63$ accounted for $0.5 \%$ of the cellular dry weight while ergosterol, as the free sterol, was present as $1.8 \%$ of the cellular dry weight. Previous extraction of shaking cultures grown in this medium indicated no component at RRT $=1.63$ (Shapiro \& Gealt, 1982).

\section{DISCUSSION}

Static cultures of the fungus $A$. nidulans grown on a defined glucose/salts medium produced the pentacyclic triterpenoid alcohol $\beta$-amyrin. While TLC, GLC, and HPLC retention characteristics were very suggestive, the MS fragmentation coupled with the ${ }^{1} \mathrm{H}$ NMR spectrum provide compelling evidence for our identification. The presence of $\beta$-amyrin in A. nidulans was unexpected because, although common in plants, reports of its presence in the fungi are extremely rare. It has been reported as a constituent of the parasitic coffee fungus Balanophora indica (Narayanan et al., 1976), but may be a product of the plant host. The biochemical mechanism of synthesis of this compound has been demonstrated in the pea, Pisum sativum (Baisted et al., 1962; Capstack et al., 1965) indicating that $\beta$-amyrin is an alternative cyclization product of squalene, in photosynthetic organisms to cycloartenol and in non-photosynthetic organisms to lanosterol.

The role of $\beta$-amyrin in $A$. nidulans remains unknown. It has been reported as a membrane component in plants (Kemp \& Mercer, 1968; Janiszowska \& Kasprzyk, 1977), although it is generally sequestered in the resins, latex and waxes (Robinson, 1963). An attempt to substitute it for a sterol in the membranes of anaerobic Saccharomyces cerevisiae, which cannot produce sterols, was unsuccessful (Sekula, 1979) although it can replace sterols as a growth stimulant in the fungus Phytophthora cactorum (Nes \& Heftmann, 1981). It has been shown that many triterpenoids, especially triterpene glycosides, have antifungal activity (Anisimov et al., 1979). Although $\beta$-amyrin was not tested by these authors, it might serve as an antifungal agent or a precursor of such an agent. Production of such a factor may give $A$. nidulans a competitive advantage in the natural environment.

Synthesis of both lanosterol and $\beta$-amyrin from squalene probably requires two different enzymes with which the precursor may interact. Since $\beta$-amyrin was not observed when flasks were shaken during the culture period (Shapiro \& Gealt, 1982), we suggest that the enzyme responsible for this alternative squalene cyclization was induced by some environmental factor(s). Investigation of these factors and of their effect on cellular lipid metabolites and protein components is being pursued.

I would like to thank W. R. Nes for his interest and support during this project, as well as T. Lindley and J. R. Landrey for their technical help in various phases of this study. The proton nuclear magnetic resonance spectra were obtained at the National Institutes of Health sponsored NMR facility at the University of Pennsylvania.

\section{REFERENCES}

AdleR, J. H., Gealt, M. A., Nes, W. D. \& NES, W. R. (1981). Growth characteristics of Saccharomyces cerevisiae and Aspergillus nidulans when biotin is replaced by aspartic and fatty acids. Journal of General Microbiology 122, 101-107.
Anisimov, M. M., Shcheglov, V. V., Strigina, L. I., Chetyrina, N. S., Uvarova, N. I., Oshitok, G. I., Alad'ina, N. G., Vecherko, L. P., Zorina, A. D., Matyukhina, L. G. \& Saltykova, I. A. (1979). Chemical structure and antifungal activity of a num- 
ber of triterpenoids. Izvestiya Akademii nauk SSSR, seriya biologicheskaya $\mathbf{0 ( 4 ) , 5 7 0 - 5 7 5 . ~}$

Baisted, D. J., Capstack, E., JR \& Nes, W. R. (1962). The biosynthesis of $\beta$-amyrin and $\beta$-sitosterol in germinating seeds of Pisum sativum. Biochemistry 1, 537-541.

BOAR, R. B. \& ALLEN, J. (1973). $\beta$-Amyrin triterpenoids. Phytochemistry 12, 2571-2578.

Budzikiewicz, H., Djerassi, C. \& Williams, D. H. (1964). Structure Elucidation of Natural Products by Mass Spectrometry, Vol. II: Steroids, Terpenoids, Sugars, and Miscellaneous Classes. San Francisco: Holden-Day.

Capstack, E., JR, Rosin, N., Blondin, G. A. \& Nes, W. R. (1965). Squalene in Pisum sativum. Journal of Biological Chemistry 240, 3258-3263.

Gealt, M. A., Sheir-Neiss, G., \& Morris, N. R. (1976). The isolation of nuclei from the filamentous fungus Aspergillus nidulans. Journal of General Microbiology 94, 204-210.

JANISZOWSKA, W. \& KASPRZYK, Z. (1977). Intracellular distribution and origin of pentacyclic triterpenes in Calendula officinalis leaves. Phytochemistry 16, 1919-1923.

KATES, M. (1975). Techniques of Lipidology: Isolation,
Analysis and Identification of Lipids. New York: American Elsevier Publishing Co.

Kemp, R. J. \& Mercer, E. I. (1968). Studies on the sterols and sterol esters of the intracellular organelles of maize shoots. Biochemical Journal 110, 119-125.

Narayanan, C. R., Kulkarni, A. K., Quisim, C. \& WADIA, M. S. (1976). Chemical examination of the rhizomes of the coffee fungus, Balanophora indica Wall. Indian Journal of Chemistry 14B, 906-907.

Nes, W. D. \& HeFtManN, E. (1981). A comparison of triterpenoids with steroids as membrane components. Journal of Natural Products 44, 377-400.

NEs, W. R. \& MCKEAN, M. L. (1977). Biochemistry of Steroids and Other Isopentenoids. Baltimore: University Park Press.

RoBINSON, T. (1963). The Organic Constituents of Higher Plants: Their Chemistry and Interrelationships. Minneapolis: Burgess Publishing Company.

SeKulA, B. (1979). Structural specificity of sterols in membranes of Saccharomyces cerevisiae. Ph.D. dissertation, Drexel University, Philadelphia, Pennsylvania, U.S.A.

Shapiro, B. E. \& Gealt, M. A. (1982). Ergosterol and lanosterol from Aspergillus nidulans. Journal of General Microbiology 128, 1053-1056. 